\title{
Operational flood-forecasting in the Piemonte region - development and verification of a fully distributed physically-oriented hydrological model
}

\author{
D. Rabuffetti ${ }^{1,2}$, G. Ravazzani ${ }^{2}$, S. Barbero ${ }^{1}$, and M. Mancini ${ }^{2}$ \\ ${ }^{1}$ ARPA Piemonte - Monitoring and forecasting area, 10135 Torino, Italy \\ ${ }^{2}$ DIIAR-CIMI Politecnico di Milano, Milano, Italy
}

Received: 11 January 2008 - Revised: 8 July 2008 - Accepted: 6 March 2009 - Published: 16 March 2009

\begin{abstract}
A hydrological model for real time flood forecasting to Civil Protection services requires reliability and rapidity. At present, computational capabilities overcome the rapidity needs even when a fully distributed hydrological model is adopted for a large river catchment as the Upper Po river basin closed at Ponte Becca (nearly $40000 \mathrm{~km}^{2}$ ). This approach allows simulating the whole domain and obtaining the responses of large as well as of medium and little sized sub-catchments. The FEST-WB hydrological model (Mancini, 1990; Montaldo et al., 2007; Rabuffetti et al., 2008 ) is implemented. The calibration and verification activities are based on more than 100 flood events, occurred along the main tributaries of the Po river in the period 2000-2003. More than 300 meteorological stations are used to obtain the forcing fields, 10 cross sections with continuous and reliable discharge time series are used for calibration while verification is performed on about 40 monitored cross sections. Furthermore meteorological forecasting models are used to force the hydrological model with Quantitative Precipitation Forecasts (QPFs) for $36 \mathrm{~h}$ horizon in "operational setting” experiments. Particular care is devoted to understanding how QPF affects the accuracy of the Quantitative Discharge Forecasts (QDFs) and to assessing the QDF uncertainty impact on the warning system reliability. Results are presented either in terms of QDF and of warning issues highlighting the importance of an "operational based" verification approach.
\end{abstract}

\section{Introduction}

The Piemonte Region, in the north-west of Italy, covers the major part of the upper Po river basin closed at Ponte Becca (Ticino and Po rivers junction). The environment is prone to

Correspondence to: D. Rabuffetti

(davide.rabuffetti@arpa.piemonte.it) hydrological risk: rapid responding streams and rivers come down from the Alps into the flat Po river valley where lots of human activities take place. Landslides and erosion involve the steep hillslopes often amplifying the floods damages because of high sediment and wood transport.

An operational service for flood forecasting has been managed since year 2000 by Piemonte Region technical services (now moved to ARPA Piemonte). A flood forecasting bulletin is issued every time a meteorological early warning is addressed to the civil protection service. The hazard level is assessed referring to codified flood scenarios (Code 1: ordinary; Code 2: low hazard; Code 3: high hazard) for a selection of 24 river cross sections along the main rivers in the region (Rabuffeti and Barbero, 2004). At present the flood forecasting system is based on MIKE FLOODWATCH system (DHI, 2006) and it is organised in a standard architecture (Todini, 2005). QDFs are mainly addressed to the main rivers describing the complex hydraulic phenomena while the hydrological rainfall-runoff transformation is simplified.

An essential development for this bulletin requires to increase the number of the selected cross sections studying minor rivers and tributaries as well, improving the hydrological modelling in order to describe little catchments processes. The development and testing activities of the fully distributed hydrological model FEST-WB are here presented. In particular, this communication highlights: the performance of the hydrologic model in off-line simulations; the influence of QPF on the accuracy of QDF; the reliability of the derived flood scenario forecasts for civil protection purposes. About this last point, it is important to keep in mind endusers and stake-holders practices: discharge forecast errors are not very crucial if the flood scenario is correctly identified; missed alarms are worse than false alarms; uncertainties need quantifying (Buizza et al., 2007). 


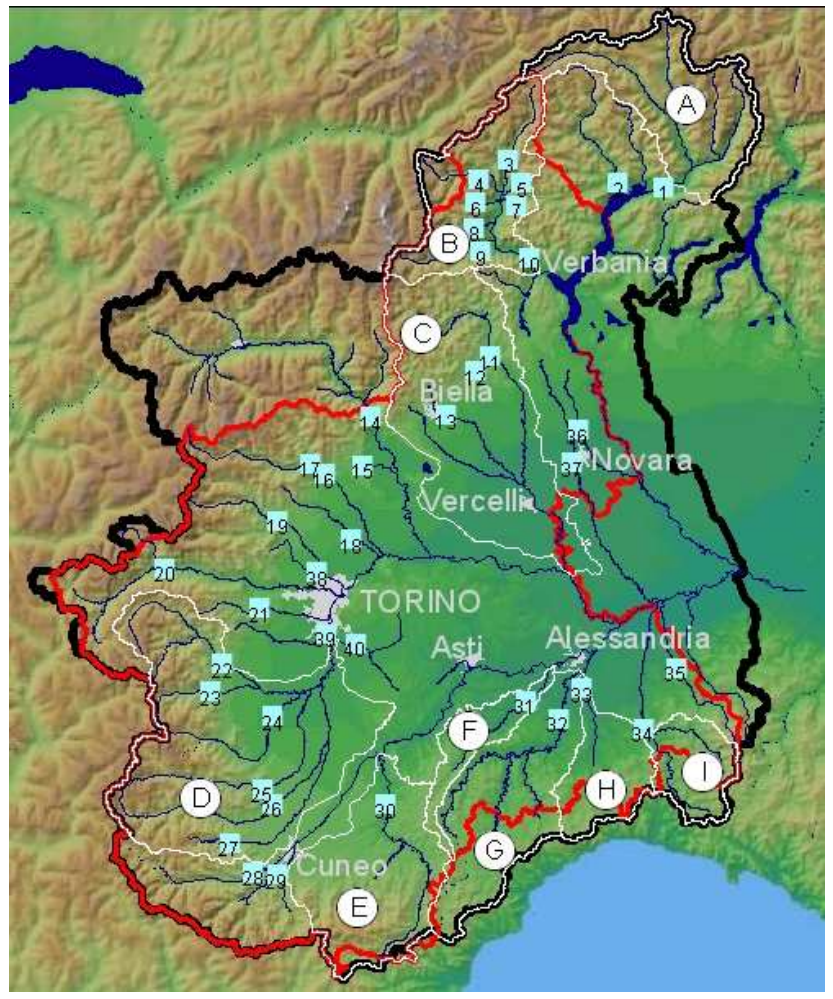

Fig. 1. Upper Po river basin (black line), Piemonte region boundaries(red) and calibration catchments (white) (Table 1). Verification cross sections for the operational case study (light blue squares) are located inside the calibration catchments as well as outside.

\section{Calibration and verification of the FEST-WB model}

The FEST-WB (Rabuffetti et al., 2008) is a fully distributed hydrological flood model with a continuous soil moisture accounting. The main physical processes addressed are: infiltration (Ravazzani et al., 2007), evapotranspiration (Priestley-Taylor, 1972), snow accumulation and melting (Tarboton et al., 1994) and flow routing (Montaldo et al., 2007).

Continuous discharge observations for the whole period are available at 10 cross sections which define the catchments where the calibration focuses on (Table 1). More than 300 meteorological stations are used to obtain the forcing fields on the domain. The calibration period is year 2000 while the validation period lasts from the January 2001 to December 2003. All the flood events in which the flood peak is greater than the 5 years return period value are selected.The results of the comparison between observation and simulation in terms of flood peak and flood wave volume are showed in Table 2. Note that, because of the goal of the application, the verification focuses on flood events even though the model is continuous. Both flood peak and volume forecasts are nearly unbiased. The results are satisfactory but the standard deviation of relative errors is quite high. This means that some over and under-estimated forecasts can be produced.

\section{QDF performance}

The off-line simulations in paragraph 2 can be considered as QDF forced by 'perfect' QPF showing both the hydrological model and the warning system reference performance for the period 2000-2003. Correspondingly, to evaluate the "online" QDF performance, two verification approaches are here presented with different hydro-meteorological chains both based on FEST-WB, which is coupled with: A - operational QPF (obtained by meteorological runs issued by different operational centres, see 3.1) for November 2002 (River Floods Case); B - the operational meteorological forecasts (obtained by the operational regional service, see 3.2 ) in the period 2000-2003 (Operational Case).

Hydrological initial conditions are taken from the same continuous simulation used for verification. 40 cross section (drained catchments surfaces range from $80 \mathrm{~km}^{2}$ to $2000 \mathrm{~km}^{2}$ ) are selected for QDF verification (Table 3).

\subsection{November 2002: River Floods Case study}

During the verification period, heavy and prolonged rainfall caused a number of river floods in Piemonte region on the periods: $14-18$ November and 22-26 November 2002. For this specific events, three different meteorological runs are used to force the hydrological model. The meteorological models are: LAMI with 2 different parameterisations, and the operational ECWMF Global Model (details in Rabuffetti and Milelli, 2005).

Comparing Tables 2 and 4, one can notice that the good behaviour of the hydrologic model is heavily affected by the unsatisfactory performance of the QPF (Bartholmes and Todini, 2005; Kobold and Sušelj, 2005). The global model QPF produces, due to its large space-time scales, the highest underestimation of flood peaks. A general underestimation trend is common to all QPF and QDF (Ferraris et al., 2002; Cluckie et al., 2006; Vincendon et al., 2008).

\subsection{Period 2000-2003: Operational Case study}

The full period is studied in "operational" settings, performing 134 hydrological runs, one for each day in which at least one of the selected flood events occurred (considering 40 cross sections we get a total number of 5360 cases for the analysis). QDF are forced with QPF daily issued by the regional meteorological service for the civil protection Warning bulletin. These QPFs refer to the alert areas defined in the civil protection plan and consist of $6 \mathrm{~h}$ cumulated mean area rainfall (Rabuffetti and Barbero, 2004).

Comparing Tables 2 and 5, one can notice that the standard deviation of the simulation error shows a strong increase. 
Table 1. Catchments and events. See Fig. 1 for geographical reference by Id.

\begin{tabular}{llllcc}
\hline Id. & River & Area $\left[\mathrm{km}^{2}\right]$ & Cross-section & \multicolumn{2}{c}{ Considered events } \\
\hline & & & & Calibration & Verification \\
A & Ticino & 1624 & Bellinzona & 4 & 10 \\
B & Toce & 1531 & Condoglia & 3 & 12 \\
C & Sesia & 2606 & Palestro & 4 & 8 \\
D & Po & 3960 & Carignano & 3 & 4 \\
E & Tanaro & 1457 & Farigliano & 5 & 6 \\
F & Belbo & 421 & Castelnuovo B. & 4 & 7 \\
G & Bormida & 1523 & Cassine & 4 & 20 \\
H & Orba & 750 & Casalcermelli & 5 & 11 \\
I & Scrivia & 617 & Serravalle & 5 & 7 \\
\hline
\end{tabular}

Table 2. Hydrological model reference performance.

\begin{tabular}{lrr}
\hline & $\begin{array}{r}\text { Flood peak } \\
\text { relative error }\end{array}$ & $\begin{array}{r}\text { Flood volume } \\
\text { relative error }\end{array}$ \\
\hline Mean & 7.41 & -0.89 \\
Standard deviation & 64.96 & 46.70 \\
$\mathrm{CV}$ & 8.77 & -52.31 \\
\hline
\end{tabular}

This means that the good behaviour of the hydrologic model calibrated on 10 catchments is not so good considering the full set of 40 verification cross sections (Fig. 1), even considering it is still nearly unbiased. Furthermore the mean error significantly increases when QPF forcing is used. However the influence of QPF errors on QDF is not so simple to understand because QPF overestimation bias doesn't correspond to a similar QDF bias. This problem is probably related to a general underestimation of rainfall peaks in the QPF resulting in too smooth rainfall fields (mean area rainfall on alert areas) and to underestimation of the basin response.

\section{Warning system performance}

To understand how QDF can drive the warning system, each peak flood forecasted can be converted into a flood scenario. In fact, it is a common procedure in civil protections plans to define hazard scenarios on the basis of discharge thresholds characteristic of each cross section. In Piemonte warning system: when the discharge reaches the "code 2 " value the flood wave is generally inside the riverbed but interaction with levees and bridges can cause local dangers; when it reaches the "code 3" value the flood wave can produce extensive flooding and serious damages to structures along the river determining very hazardous conditions. In this way, each QDF becomes a hazard forecast. Using a verification approach based on contingency tables (Murphy, 1993) and related categorical statistics (bias, hit rate and threat score), one can compare the performance of the different modelling chains.

In Fig. 2 the results for the warning system performance are shown. First it is important to highlight that the reference performance is better for the "Code 2" alerts considering bias but hit rate and threat score remain good also for "Code 3". In the River Flood Case, which presents only "Code 2" scenario, the hydrologic model performance is very high while the QDF are quite poor, especially when forcing field come from the global model. This means that QPF played a big role in affecting the overall system quality. Furthermore comparing the reference and the Operational sets, one can notice that using the model on the full set of verification cross sections produce a general decrease of the warning system reliability, in accordance with the error analysis, even though the performance remains acceptable. In this case, the impact of QDF is significant but not as much important as in the River Flood Case.

To get deeper into the operational performance understanding, the 5360 QDFs analysed have been classified accordingly to whether forecasted and/or observed precipitation overcomes a certain threshold $(\mathrm{TH}=30-80 \mathrm{~mm}$ per day averaged at catchment scale are used). So that one can evaluate the system when a certain precipitation event is observed $(\mathrm{Po}>\mathrm{TH})$, forecasted $(\mathrm{Pf}>\mathrm{TH})$ or correctly forecasted $((\mathrm{Pf}>\mathrm{TH}) \mathrm{U}(\mathrm{Po}>\mathrm{TH}))$.

In Fig. 3 these results are presented using again the same performance indices for comparison. The differences are not 
Table 3. Verification cross-sections. See Fig. 1 for geographical reference by Id.

\begin{tabular}{|c|c|c|c|c|c|c|c|}
\hline Id & River & CrossSection & Area $\left[\mathrm{km}^{2}\right]$ & Id & River & Cross Section & Area $\left[\mathrm{km}^{2}\right]$ \\
\hline 1 & Ticino & Bellinzona & 1624 & 21 & Sangone & Trana & 125 \\
\hline 2 & Maggia & Solduno & 905 & 22 & Chisone & S. Martino & 575 \\
\hline 3 & Toce & Pontemaglio & 378 & 23 & Pellice & Luserna S. G. & 237 \\
\hline 4 & Diveria & Crevola & 720 & 24 & Po & Carde' & 604 \\
\hline 5 & Isorno & Pontetto & 71 & 25 & Maira & Busca & 593 \\
\hline 6 & Bogna & Ponte Caddo & 84 & 25 & Varaita & Rossana & 436 \\
\hline 7 & Melezzo & Masera & 64 & 27 & Grana & Monterosso & 114 \\
\hline 8 & Ovesca & Villadossola & 165 & 28 & Stura di D. & Gaiola & 590 \\
\hline 9 & Anza & Piedimulera & 274 & 29 & Gesso & Borgo S. D. & 554 \\
\hline 10 & Toce & Candoglia & 1531 & 30 & Tanaro & Farigliano & 1457 \\
\hline 11 & Sesia & Borgosesia & 690 & 31 & Belbo & Castelnuovo & 421 \\
\hline 12 & Sessera & Pray & 120 & 32 & Bormida & Cassine & 1523 \\
\hline 13 & Cervo & Vigliano & 160 & 33 & Orba & Casal Cermelli & 750 \\
\hline 14 & D. Baltea & Tavagnasco & 3393 & 35 & Scrivia & Serravalle & 617 \\
\hline 15 & Chiusella & Parella & 157 & 35 & Curone & Volpedo & 170 \\
\hline 16 & Orco & Cuorgè & 664 & 36 & Terdoppio & Caltignaga & 98 \\
\hline 17 & Soana & Pont & 217 & 37 & Agogna & Novara & 206 \\
\hline 18 & Malone & Brandizzo & 312 & 38 & Ceronda & Venaria & 164 \\
\hline 19 & Stura di L. & Lanzo & 635 & 39 & Chisola & La Loggia & 443 \\
\hline 20 & D. Riparia & Susa & 901 & 40 & Banna & Santena & 374 \\
\hline
\end{tabular}

Table 4. Hydrological model performance for the River floods case study.

\begin{tabular}{|c|c|c|c|c|}
\hline & & $\begin{array}{r}\text { Flood peak } \\
\text { relative error [\%] }\end{array}$ & $\begin{array}{r}\text { Flood volume } \\
\text { relative error [\%] }\end{array}$ & $\begin{array}{r}\mathrm{QPF} \\
\text { relative error }[\%]\end{array}$ \\
\hline \multirow{4}{*}{ Simulation } & Mean & 6.65 & 2.9 & \\
\hline & Standard deviation & 20,05 & 32,65 & \\
\hline & $\mathrm{CV}$ & 3.05 & -18.05 & \\
\hline & Absolute mean & 39.65 & 20.9 & \\
\hline \multirow{4}{*}{ ecmwf } & Mean & -39.95 & -29.9 & -37.6 \\
\hline & Standard deviation & 43.85 & 42.55 & 25.5 \\
\hline & $\mathrm{CV}$ & -1.15 & -1.45 & -0.7 \\
\hline & Absolute mean & 47.3 & 28.15 & 39.3 \\
\hline \multirow{4}{*}{ s1 } & Mean & -28.1 & -41.1 & -46.8 \\
\hline & Standard deviation & 52.5 & 35.3 & 27.25 \\
\hline & $\mathrm{CV}$ & -2 & -0.85 & -0.6 \\
\hline & Absolute mean & 42.55 & 45 & 46.9 \\
\hline \multirow{4}{*}{$\mathrm{s} 2$} & Mean & -32.75 & -42.2 & -44.3 \\
\hline & Standard deviation & 40.85 & 35.5 & 29.35 \\
\hline & $\mathrm{CV}$ & -1.25 & -0.85 & -0.65 \\
\hline & Absolute mean & 50.85 & 36.5 & 44.6 \\
\hline
\end{tabular}




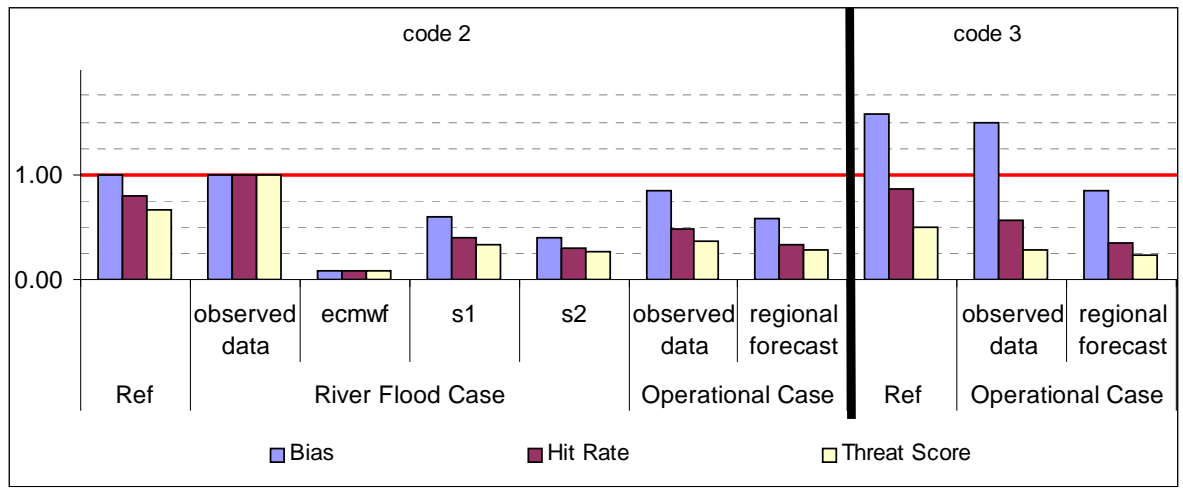

Fig. 2. Performance of the warning system for the different modelling chains and case studies. The red line indicates the optimal value for the three indices.
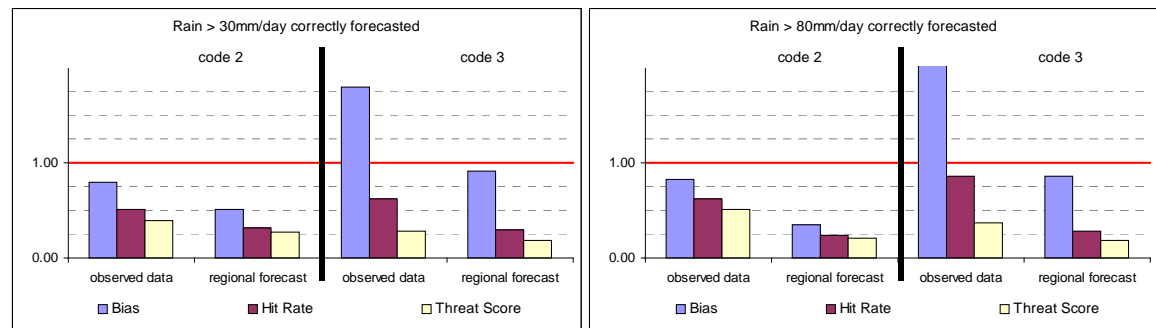

$(\mathrm{Pf}>30) \mathrm{U}(\mathrm{Po}>30): 902$ cases

$(\mathrm{Pf}>80) \mathrm{U}(\mathrm{Po}>80): 89$ cases
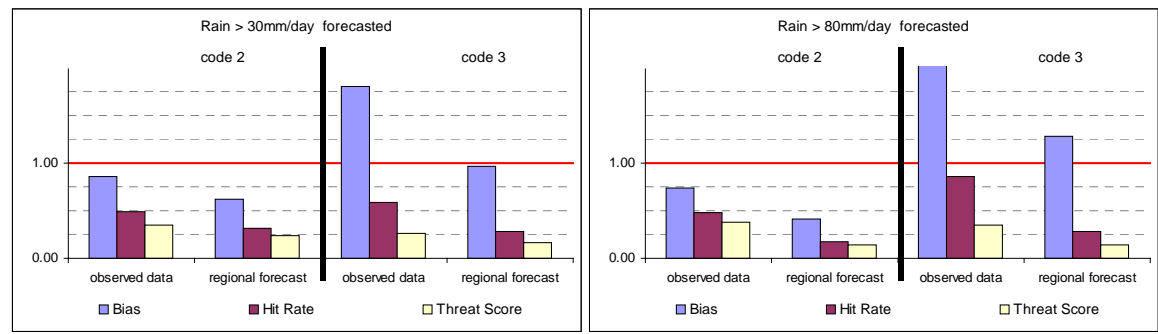

(Pf>30): 2071 cases

(Pf>80): 216 cases

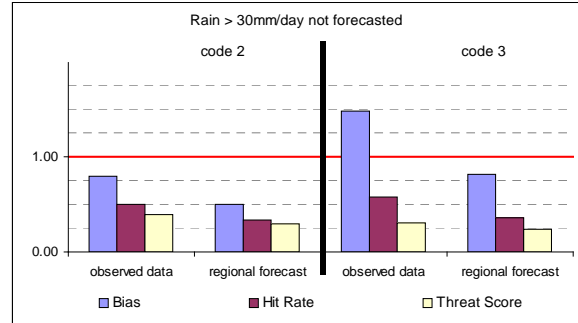

(Po>30): 1467 cases

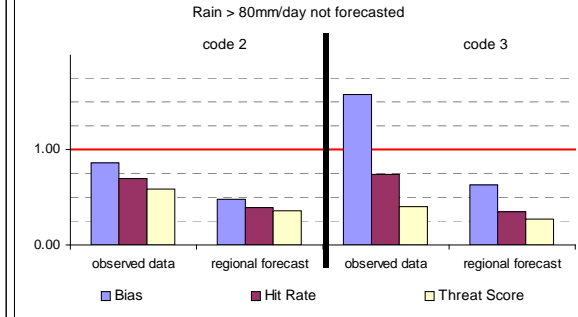

(Po>80): 195 cases

Fig. 3. Performance of the warning system in Operational Case study and dependence on the meteorological warning. The number of cases for each class is indicated. 
Table 5. QDF error analysis for the operational case study.

\begin{tabular}{cccc}
\hline & & $\begin{array}{c}\text { Flood peak } \\
\text { relative error [\%] }\end{array}$ & $\begin{array}{c}\text { QPF } \\
\text { relative error [\%] }\end{array}$ \\
\hline \multirow{3}{*}{ Simulation } & Mean & -4.0 & \\
& Standard deviation & 201.4 & \\
& CV & -50.3 & \\
\hline \multirow{3}{*}{ Regional } & Absolute mean & 84.0 & 28.0 \\
& Mean & -14.0 & 207.0 \\
& Standard deviation & 226.0 & 7.4 \\
& CV & -16.1 & 78.0 \\
\hline
\end{tabular}

so clear, anyway, a general impact of QPF on the system is present confirming what previously stated. It is also important to highlight the poor performance of the system when considering the case of forecasted precipitation greater than $80 \mathrm{~mm} /$ day. These are the cases when heavy overestimation of QPF is transferred to QDF. This situation is the most common in operational activity (as proved by its occurrence frequency) and severely impacts on the overall reliability. Furthermore it is the case generally neglected in verifications based on case studies which can be often misleading to drive general conclusion about the warning system consistency.

\section{Conclusions}

The work presented shows how a fully distributed hydrological model can be effectively adopted for operational flood forecasting. Computational time is not a limit and the performance of the off-line simulations is acceptable. Calibration requires a large amount of meteorological data and discharge time series. If they are available only on a sub-set of catchments, as in the Piemonte case, calibration can be less effective in improving the model accuracy.

Simulation results are analysed both in terms of discharge and hazard scenario forecast highlighting that the real magnitude of QDF errors is not strongly correlated to the performance in terms of alert issues. It means that even significant errors in QDF can yet produce an acceptable flood scenario detection.

The hydrometeorological system is verified following two approaches based: on case studies and on full operational chaining. The differences in the results obtained enhance that "case study" verification is useful to understand the specific model performance but can be misleading when focusing on operational systems. In fact, QPF uncertainty generally impacts on the warning system but, when considering a long period this impact seems less important with respect to specific cases.
Finally, the operational verification highlights how QPF affects the reliability of both QDF and the warning system in particular when high precipitations are overestimated. This is very common in operational activity nevertheless it is generally neglected in "case study" verifications enhancing the need of long period operational verification to drive general conclusion about the warning system consistency.

Acknowledgements. This work was funded in the framework of the AMPHORE 2003-03-4.3-I-079 EU-INTERREG IIIB MEDOCC "Application des Methodologies de Previsions Hydrometeorologiques Orientees aux Risques Environnementaux". The authors thank also T. Leoni and P. Peduzzi for their contribution in simulation and result analysis.

Edited by: G. Roth

Reviewed by: one anonymous referee

\section{References}

Bartholmes, J. and Todini, E.: Coupling meteorological and hydrological models for flood forecasting, Hydrol. Earth Syst. Sci., 9, 333-346, 2005, http://www.hydrol-earth-syst-sci.net/9/333/2005/.

Buizza, R., Asensio, H., Balint, G., Bartholmes, J., Bliefernicht, J., Bogner, K., Chavaux, F., de Roo, A., Donnadille, J., Ducrocq, V., Edlund, C., Kotroni, V., Krahe, P., Kunz, M., Lacire, K., Lelay, M., Marsigli, C., Milelli, M., Montani, A., Pappenberger, F., Rabuffetti, D., Ramos, M.-H., Ritter, B., Schipper, J. W., Steiner, P., Thielen-Del Pozzo, J., and Vincendon, B.: EURORISK/PREVIEW report on the technical quality, functional quality and forecast value of meteorological and hydrological forecasts, ECMWF Tech. Memorandum 516, ECMWF Research Dep., Reading, 1-63, 2007.

Xuan, Y., Cluckie, I. D., and Wang, Y.: Uncertainty analysis of hydrological ensemble forecasts in a distributed model utilising short-range rainfall prediction, Hydrol. Earth Syst. Sci., 13, 293 303, 2009, http://www.hydrol-earth-syst-sci.net/13/293/2009/.

DHI: FLOODWATCH, User Guide and Reference Manual, DHI Water \& Environment, Horsholm, Denmark, 2006. 
Kobold, M. and Sušelj, K.: Precipitation forecasts and their uncertainty as input into hydrological models, Hydrol. Earth Syst. Sci., 9, 322-332, 2005, http://www.hydrol-earth-syst-sci.net/9/322/2005/.

Ferraris, L., Rudari, R., and Siccardi, F.: The Uncertainty in the Prediction of Flash Floods in the Northern Mediterranean Environment, J. Hydrometeorol., 3, 2002.

Murphy, A.H.: What is a good forecast? An essay on the nature of goodness in weather forecasting, Weather Forecast., 8, 281-293, 1993.

Mancini, M.: La modellazione distribuita della risposta idrologica: effetti della variabilità spaziale e della scala di rappresentazione del fenomeno dell'assorbimento, PhD thesis, Politecnico di Milano, Milan, Italy, 1990 (in Italian).

Montaldo, N., Ravazzani, G., and Mancini, M.: On the prediction of the Toce alpine basin floods with distributed hydrologic models, Hydrol. Process., 21, 608-621, 2007.

Priestley, C. H. B. and Taylor, R. G.: On the assessment of surface heat flux and evaporation using large scale parameters. Mon. Weather Rev., 100, 81-92, 1972.

Rabuffetti, D. and Barbero, S.: The Piemonte Region Meteohydrological Alert Procedure and the Real Time Flood Forecasting System. Associated Programme on Flood Management, WMO, www.apfm.info/case_studies.htm\#europe, 2004.

Rabuffetti, D., Ravazzani, G., Corbari, C., and Mancini, M.: Verification of operational Quantitative Discharge Forecast (QDF) for a regional warning system - the AMPHORE case studies in the upper Po River, Nat. Hazards Earth Syst. Sci., 8, 161-173, 2008, http://www.nat-hazards-earth-syst-sci.net/8/161/2008/.
Rabuffetti, D. and Milelli, M.: The hydro-meteorological chain in Piemonte region, North Western Italy - analysis of the HYDROPTIMET test cases, Nat. Hazards Earth Syst. Sci., 5, 845852, 2005, http://www.nat-hazards-earth-syst-sci.net/5/845/2005/.

Ravazzani, G., Mancini, M., Giudici, I., and Amadio, P.: Effects of soil moisture parameterization on a real-time flood forecasting system based on rainfall thresholds, in: Quantification and Reduction of Predictive Uncertainty for Sustainable Water Resources Management, edited by: Boegh, E., Kunstmann, H.,Wagener, T., Hall, A., Bastidas, L., Franks, S., Gupta, H., Rosbjerg, D., and Schaake, J., IAHS Publ. 313, 407-416, 2007.

Tarboton, D. G., Chowdhury, T. G., and Jackson, T. H.: "A Spatially Distributed Energy Balance Snowmelt Model”, in: Biogeochemistry of Seasonally Snow-Covered Catchments, edited by: Tonnessen, K. A., Williams, M. W., and Tranter, M., Proceedings of a Boulder Symposium, 3-14 July, IAHS Publ. no. 228, 141-155, 1995.

Todini, E.: Rainfall-Runoff Models for Real-Time Forecasting, Encyclopedia of Hydrological Sciences - Part 11. Rainfall-Runoff Modeling, J. Wiley \& Sons, Ltd, 1869-1896, 2005.

Vincendon, B., Ducrocq, V., Dierer, S., Kotroni, V., Le Lay, M., Milelli, M., Quesney, A, Saulnier, G. M., Rabuffetti, D., Bouilloud, L., Chancibault, K., Anquetin, S., Lagouvardos, K., and Steiner, P.: Flash flood forecasting within the PREVIEW project: value of high-resolution hydrometeorological coupled forecast, Meteorol. Atmos. Phys., doi:10.1007/s00703-008-0315-6, 2008. 